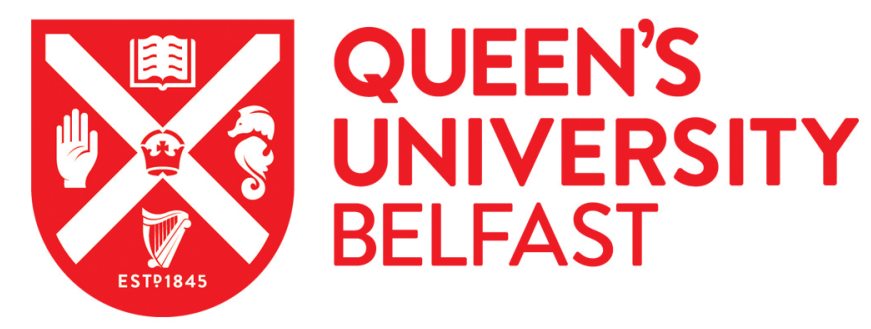

\title{
Analysis of physiological changes related to emotions during a zipline activity
}

Dupré, D., Andelic, N., Moore, D. S., Morrison, G., \& McKeown, G. J. (2020). Analysis of physiological changes related to emotions during a zipline activity. Sports Engineering, 23(1), [15]. https://doi.org/10.1007/s12283-02000328-9

Published in:

Sports Engineering

Document Version:

Peer reviewed version

Queen's University Belfast - Research Portal:

Link to publication record in Queen's University Belfast Research Portal

Publisher rights

Copyright 2020 Springer. This work is made available online in accordance with the publisher's policies. Please refer to any applicable terms of use of the publisher.

\section{General rights}

Copyright for the publications made accessible via the Queen's University Belfast Research Portal is retained by the author(s) and / or other copyright owners and it is a condition of accessing these publications that users recognise and abide by the legal requirements associated with these rights.

Take down policy

The Research Portal is Queen's institutional repository that provides access to Queen's research output. Every effort has been made to ensure that content in the Research Portal does not infringe any person's rights, or applicable UK laws. If you discover content in the Research Portal that you believe breaches copyright or violates any law, please contact openaccess@qub.ac.uk. 


\title{
Analysis of physiological changes related to emotions during a zipline activity
}

\author{
Damien Dupré · Nicole Andelic · Daniel \\ Moore • Gawain Morrison • Gary \\ McKeown .
}

Received: date / Accepted: date

\begin{abstract}
Despite the popularity of physiological wearable sensors in sport activities to provide feedback on athletes' performance, understanding the factors influencing changes in athletes' physiological rhythms remains a challenge. Changes in physiological rhythms such as heart rate, breathing rate or galvanic skin response can be due to both physical exertion and psychoemotional states. Separating the influence of physical exertion and psychoemotional states in activities that involves both is complicated. As a result, the influence of psycho-emotional states is usually underestimated. In order to identify the specific influence of psycho-emotional states in physiological rhythm changes, 28 participants were asked to participate in a zipline activity, which involve little or no physical exertion while stimulating psycho-emotional states. By using nonlinear analyses, results show that specific changes in phys-
\end{abstract}

This research was supported and led by Sensum Ltd. in collaboration with Queen's University Belfast.

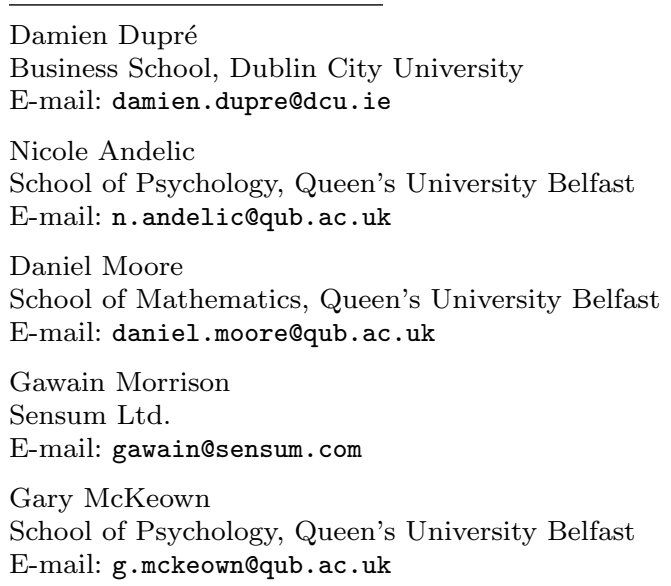


iological rhythms can be associated with phases in ziplining, after which they can be related to emotional states felt during the activity. Regarding data analysis of wearable sensors, this paper presents a workflow to identify significant physiological patterns across multiple athletes performing the same outdoor activity.

Keywords Emotion · Physiology · Wearable monitoring · Multivatiate time-series · Nonlinear analysis .

Mathematics Subject Classification (2000) 62M10 - 62H12 .

\section{Introduction}

Wearable sensors are efficient tools for monitoring patients' physical [1, 2] and psychological health $[3,4]$ allowing the continuous and real-time tracking of physiological changes. The use of wearable sensors for exercise and sport performance monitoring have become common as the technology of the devices have improved [5]. Indeed, there are hundreds of commercial devices for tracking exercise or sports activities [6,7]. Performance monitoring devices are often watches, belts or smart patches for individual $[8,9]$ or team sports $[10-12]$. By using these wearable sensors and the associated software, individuals are able to measure and analyse physiological rhythms in real time during exercise and sport.

With the use of wearable sensors, physiological rhythms can be evaluated both during controlled settings such as training [13, 14], as well as during outdoor competitions. Monitoring athletes in different settings is particularly important for accurate feedback, as outdoor competitions typically involve higher stakes and different results and outcomes than training [15]. However, understanding the factors influencing changes in athletes' physiological rhythms remains a challenge. While an athlete's physical exertion is one of the main drivers of the physiological rhythms, psycho-emotional states can also influence their evolution [16]. Outdoor activities triggering highly emotional experiences are related to intense physiological changes (e.g. skydiving [17] or kitesurfing [18]). A study on mountain biking revealed that physiological changes correlated not only with athletes' speed, which increased physical exertion, but also with the perceived difficulty of the track [19]. Therefore, by monitoring physiological rhythms during an outdoor activity that involves little to no physical exertion, the present study aims to identify the specific influence of psycho-emotional states on physiological rhythms.

Among the different outdoor sports that can be analysed, the nature of the zipline activity makes it particularly suitable when examining physiological changes [20]. For example, ziplining can trigger intense emotions due to the speed and height inherent of the activity, whilst also being a controlled activity [21]. All participants of a zipline activity perform the same quasi-linear pattern 


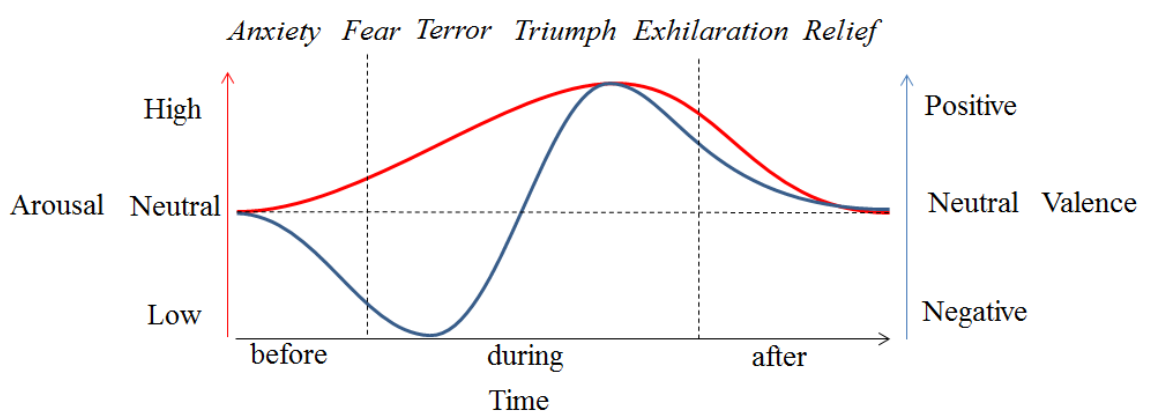

Fig. 1 Theoretical evolution of emotional states during the zipline activity according to valence and arousal dimensions [26].

of movement and are unable to deviate from it, providing a controlled environment for researchers studying physiological changes (see [22, 23]). Differences between zipline participants will affect how sensor inputs (mainly visual but also sound and vibrations) are appraised as well as the specific emotional reactions that are triggered [24]. People use a combination of experience and individual skills to manage the feelings elicited by the potential danger posed by elevated speed and height, as quickly as possible. Indeed, these physiological changes are patterns which are associated with different psychological states $[16,25]$ that follow a specific temporal evolution [19]: from anxiety to fear, terror, triumph, exhilaration and relief (Figure 1).

According to Russell [27], affective states and emotions in particular can be evaluated by their level of valence (i.e. if the emotion is positive or negative) and arousal (i.e. level of psycho-physiological activation from low to high). The dimensions of valence and arousal are key factors explaining the practice of sports and outdoor activities [26]. By monitoring these dimensions, it is possible to map the evolution of athletes' affective states throughout the practice (e.g. during motorbike driving [28], mountain biking [19], running [29], mountain hiking [30] or general training [31]). From a theoretical perspective, ziplining should induce high levels of stress just before and during the first few seconds of the activity [22, 32]. Therefore, initially a strong, negative emotional state should be triggered, which then evolves to a strong, positive emotion. This stress should also increase the physiological activation during the zipline.

By analyzing the dynamic changes of several physiological measures simultaneously it is possible to identify these individually triggered reactions. Consequently, the zipline activity provides an opportunity to measure the psycho-physiological correlates of individuals' emotional experiences during a high-intensity, controlled outdoor activity. 


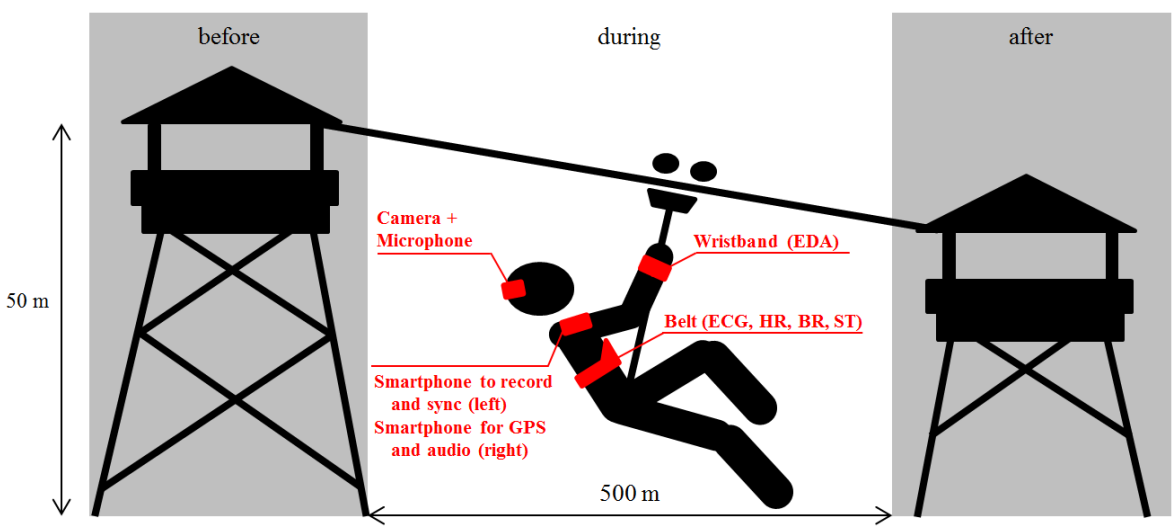

Fig. 2 Description of the multivariate physiological sensor recording set up (not to scale). $\mathrm{EDA}=$ Electrodermal Activity, $\mathrm{ECG}=$ Electrocardiogram, $\mathrm{HR}=$ Heart Rate, BR = Breathing Rate, $\mathrm{ST}=$ Skin Temperature.

\section{Method}

\subsection{Participants}

After providing their written informed consent, 30 participants volunteered for the study. This sample included 12 females and 18 males and their age distribution has a mean $(M) 28.3$ and a standard deviation $(S D)$ of 6.33 . The recruitment process included a medical check to ensure that no participants had a history of cardiac abnormalities and that they were not using cardioactive medication. Participants were informed that they could change their mind and withdraw their consent at any point during the experiment. Two participants decided not to take part in the experiment prior to the zipline task, leaving 28 participants in total. The research project and procedure received ethical approval by the School of Psychology Research Ethics Committee at Queen's University Belfast, United Kingdom (No 16-2016-17).

\subsection{Measurements}

For this experiment, the participants were equipped with five wearable sensors (Figure 2).

They wore a multiple sensor belt (Equivital EQ02, see [33, 34]) with two main components: a bio-compatible fabric embedding multiple sensors and an electronics module to gather and send data recorded by the sensors. The belt recorded participants' breathing rate (BR), external skin temperature (ST) and electrocardiogram (ECG) from which heart rate (HR) was calculated. The measurement accuracy of the Equivital EQ02 sensor belt is lower than for the gold standard device for HR monitoring from ECG peak detection. 
All artifacts included, the mean difference $(\Delta M)$ between the Equivital EQ02 and the Holter ambulatory ECG Monitor is $7.08 \mathrm{bpm}$ with a $S D$ of $17 \%$, and a Pearson correlation $(r)$ of 0.724 [34]. However, no significant difference has been found between the Equivital EQ02 and the Polar S810i HR Monitor with a $\Delta M$ of $1.2 \mathrm{bpm}$, a standard error of the estimate $(S E E)$ of 0.54 , and a $r$ of 0.98. Similarly, no significant difference has been found between the Equivital EQ02 and the ADInstruments Metabolic BR Monitor with a $\Delta M$ of $0.2 \mathrm{rpm}$, a $S E E$ of 0.19 , and a $r$ of 0.97 , as well as between the Equivital EQ02 and the ADInstruments ST Monitor with a $\triangle M$ of $-0.1^{\circ} \mathrm{C}$, a $S E E$ of 0.02 , and a $r$ of 0.98 [33].

Participants also wore a wristband with two electrodes strapped on the first phalanges of the middle and the ring fingers (Shimmer2, see [35]). The wristband and electrodes recorded participants' sudation through their electrodermal activity (EDA). The Shimmer2 sensor is considered as the gold standard wearable device for EDA measurement [36] (see also [37] for a qualitative benchmark of EDA measurement devices).

To record participants' context and vocal expression, a front-facing camera (GoPro Hero 4) and a lavalier microphone (Sennheiser) were also worn. A smartphone was also strapped to each arm of the participants. On the right arm, a smartphone (iPhone 6, iOS v8.0) with the lavalier microphone recorded sound via the application (Apogee v1.2, see [38]) as well as Global Positioning System coordinates. On the left arm, a smartphone (One Plus X, Android v6.0.1) was used to run an application recording and synchronizing the physiological outputs from the wearable devices (SYNC v1.0, see [39]).

\subsection{Procedure}

The experiment took place in Todd's Leap Activity Center based in Ballygawley, Co. Tyrone, Northern Ireland. The Todd's Leap zipline hangs 50 meters above the ground and is 500 meters long. Prior to the activity, participants were provided with safety harnesses and given full safety advice by qualified instructors. The safety advice session was also a break allowing participants to rest after climbing the stairs of the takeoff tower so as to ensure that all participants were at a physiological resting state. A period of 40 seconds was recorded before leaving the jumping off platform and 40 seconds after reaching the landing platform to allow for comparisons before, during and after the zipline activity. Due to differences in duration of the zipline activity, all the participants' time-series data was rescaled on an index from 0 to 100.

\subsection{Signal pre-processing}

Participants were omitted from further analysis if one or more physiological measurements reached exclusion criteria (Table 1), i.e. displayed measures that are not physiologically possible [40,41]. Following the application of these 
criteria, 10 participants were removed due to the presence of outliers and artifacts in their recordings. The following analyses were performed on the remaining 18 participants.

Table 1 Exclusion criteria given by unreasonably low or high physiological measures [40, 41].

\begin{tabular}{lcc}
\hline Measurement & Minimun & Maximum \\
\hline Heart Rate $(\mathrm{bpm})$ & 50 & 220 \\
Breathing Rate $(\mathrm{rpm})$ & 10 & 60 \\
Skin Temperature $\left({ }^{\circ} \mathrm{C}\right)$ & 30 & 40 \\
Electrodermal Activity $(\mu \mathrm{S})$ & 2 & 20 \\
\hline
\end{tabular}

To analyse the ECG signal, an R-peak detection algorithm was applied. Then, Heart Rate Variability (HRV) was extracted from the R-peak detection using a frequency-domain analysis technique with least asymmetric Daubechies wavelets. High Frequency HRV has been identified as a relevant feature to extract for emotion recognition [42] and the power temporal evolution in the High Frequency band has been shown to correlate with participants' emotional state $[43,44]$.

Finally, EDA data provides relevant features for analysis of participants' psychological state through the extraction of Skin Conductance Level (SCL) and Skin Conductance Response (SCR) [45-47]. SCL represents the tonic level of EDA which varies slowly over time, and can be interpreted as a representation of long-term responses to an event. In contrast, SCR represents the phasic response of EDA, and is an aggregation of EDA peaks that respond to events immediately.

\subsection{Data analysis}

Physiological time-series are challenging to analyse, mainly due to the residual distribution. A potential pattern in the residuals can indicate that linear models are not suitable for fitting physiological measurements. Therefore, a model with covariates and random effects should be implemented using Generalized Additive Mixed Models (GAMMs) to fit with nonlinear patterns [48, 49] implemented in the R-package mgcv [48, 50-53]. By estimating the degree of smoothness of a Bayesian spline smoothing using restricted maximum likelihood estimation [50, 54], GAMMs allow the identification of dynamic patterns underlying time-series while taking into account participants' idiosyncratic response as follows:

$$
Y_{i s}=\alpha_{i}+f\left(X_{s}\right)+a_{i s}+\epsilon_{i s}
$$


where $i$ is the participant index and $s$ is the time in seconds. $Y_{i s}$ represents the response variable of one of the physiological measures (i.e. either HR, HF HRV, BR, ST, SCL or SCR) assuming a quasi-Gaussian distribution for the fitting [55]. The response variable $Y_{i s}$ includes a specific intercept for each participant $\left(\alpha_{i}\right)$. A smooth effect over time $f\left(X_{s}\right)$ is applied to model (Eq 1) to predict the nonlinear evolution of the physiological measure. This smooth effect $f\left(X_{s}\right)$ is built up in basic components, called the basis functions $b_{j}\left(X_{s}\right)$, such that:

$$
f\left(X_{s}\right)=\sum_{j=1}^{k} \beta_{j} \times b_{j}\left(X_{s}\right)
$$

where the regression parameters $\beta_{j}$ are estimated by penalized likelihood maximization.

The model also includes the random effects term $a_{i s}=Z b_{i}$ where $Z$ is a random effects matrix and $b_{i}$ is a vector of random effects described by $b_{i} \sim N(0, D)$. In this, $D$ represents a covariance matrix. By adding random effects for each participant, the model assumes between-participant heterogeneity but homogeneity within a participant's data over time. The error term $\epsilon_{i s}$ is assumed to be normally and independently distributed $\epsilon_{i s} \sim N\left(0, \sigma^{2}\right)$. Because the data consists of time series, the assumption of model independence may be violated. Therefore, a residual auto-correlation structure AR-1 was added to the model error (see [56] for an application to spatio-temporal time-series):

$$
\epsilon_{i s}=\rho \epsilon_{i-1, s}+\eta_{i s}
$$

This implies the following correlation structure:

$$
\operatorname{cor}\left(\epsilon_{i s}, \epsilon_{i t}\right)= \begin{cases}1 & \text { if } s=t \\ \rho^{|t-s|} & \text { else }\end{cases}
$$

Degrees of freedom above one indicate the importance of the "smooth" term to estimate the variability of the data.

By using GAMMs it is possible to identify underlying trends in participants' physiological changes. However, even though GAMMs assess time-series changes, it does not provide a statistical analysis of where these changes happen. In contrast, a Significant Zero Crossing of the Derivatives (SiZer) approach is able to identify significant changes in the GAMM predicted values [57]. SiZer methods allow for meaningful statistical inference while doing exploratory data analysis using statistical smoothing methods [58]. The SiZer approach uses the first derivatives of GAMM predictions alongside confidence intervals as follow: 


$$
\hat{f}_{h}^{\prime}(x) \pm q \hat{S D}\left(\hat{f}_{h}^{\prime}(x)\right)
$$

where $q$ is an appropriate Gaussian quantile set to $99 \%$ point-wise confidence interval. The bandwidth parameter $h$ is a positive number that determines the estimated density of smoothing $\hat{f}[59,60]$. If the bandwidth parameter $h$ is too large, the fit has over-smoothed the data and thereby fails to detect the transition from an increasing to a flat (or possibly decreasing) function. If the bandwidth parameter $h$ is too low, the fit is influenced by a very small number of data points and overestimates changes in peaks or valleys. The SiZer method (Eq 5) identifies when the curve of the slope shows a significant alteration by evaluating when zero falls outside these confidence limits. Consequently, by analyzing significant changes in physiological rhythms during a zipline activity in which there is no or little exertion, it is possible to attribute these fluctuations to changes in participants' emotions.

\section{Results}

After removing outliers and artifacts, differences during the zipline activity phases were observed for HR, BR, HF HRV, and SCL (Figure 3). However, no difference was found between phases mean for ST and SCR. The results provided by the GAMMs showed significant changes over time for participants' HR $(F(7.36)=7.8, p<0.001)$, BR $(F(6.82)=2.37, p=0.013)$, $\operatorname{SCL}(F(8.63)=49.4, p<0.001)$ and $\operatorname{HRV}(F(2.66)=6.96, p<0.001)$ whereas the physiological measures for ST $(F(1)=0.31, p=0.578)$ and SCR $(F(1.87)=1.15, p=0.388)$ remained stable.

As an evaluation of the model fit, the Akaike Information Criterion (AIC) was calculated for a simple Generalized Additive Model without random effects or autocorrelation, a GAMM without autocorrelation and a GAMM with random effects and autocorrelation (Table 2p. The lowest AIC indicates the best model fit. The comparison of the AIC revealed that the GAMM with AR1 autocorrelation and participant as a random effect obtains the lowest AIC for each of the physiological measures.

Based on the trend prediction extracted from the GAMMs, a SiZer method was performed using a $99 \%$ point-wise confidence interval (Figure 4). Using GAMMs and SiZer methods, results indicated significant local changes in the physiological pattern, which can be associated with the sequence of predicted emotions (Table 3).

Before beginning the zipline activity, there was a significant increase in HR, BR and SCL, indicating an increase in participants' arousal due to the appraisal of potential 'danger'. During the first part of the zipline, there was a second significant increase in HR and SCL, and a significant decrease of BR. These changes can be explained by the thrill of jumping out and by the increase of zipline acceleration. In the second part of the activity, as the zipline speed decreases, participants' data showed a significant decrease in HR and 

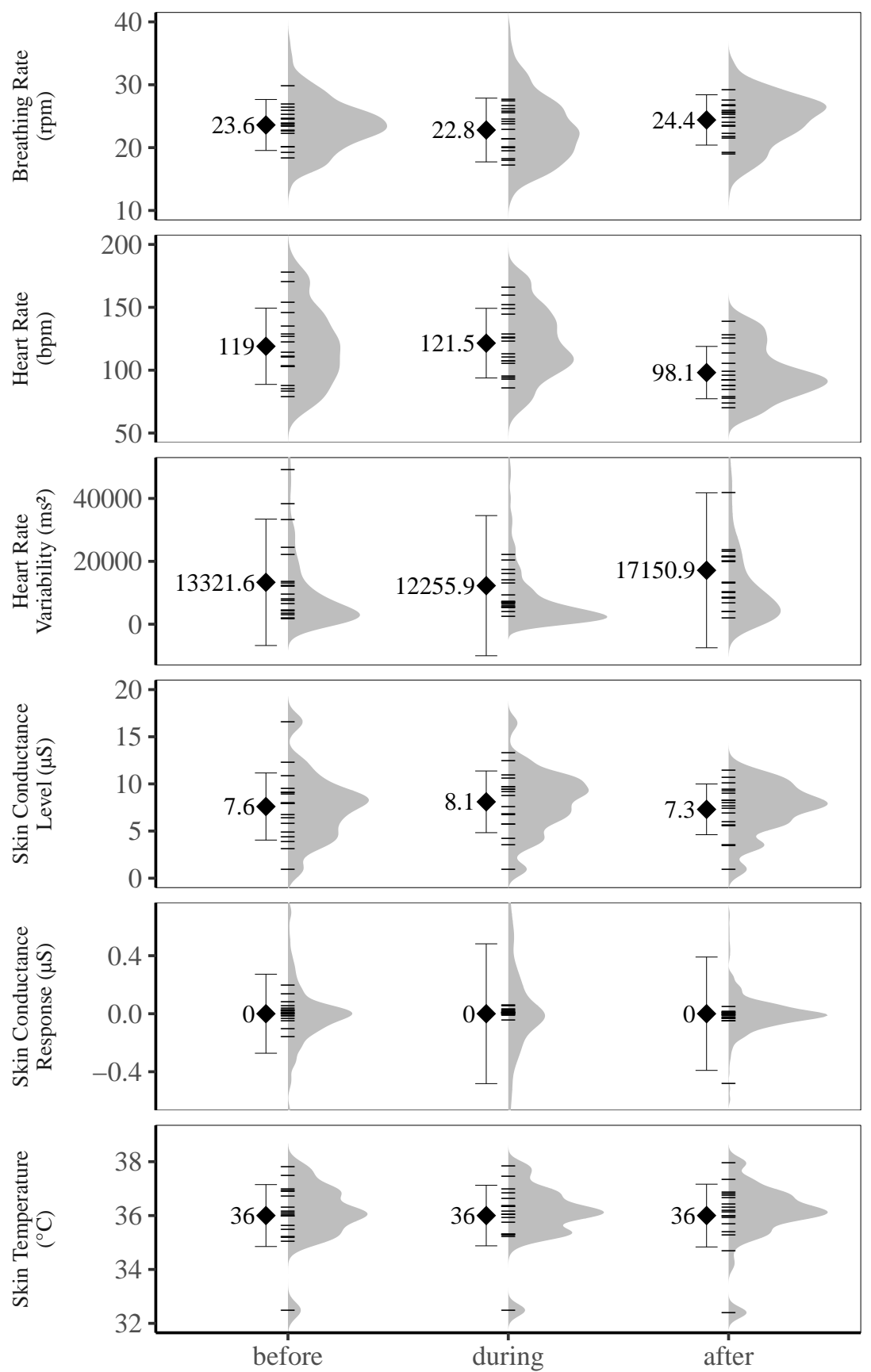

Fig. 3 Density distribution of physiological raw data for every participant (grey area) depending on the phase of the zipline activity. Square dots and error bars indicate overall mean and standard deviation. Dashes dots indicate participants' mean. 

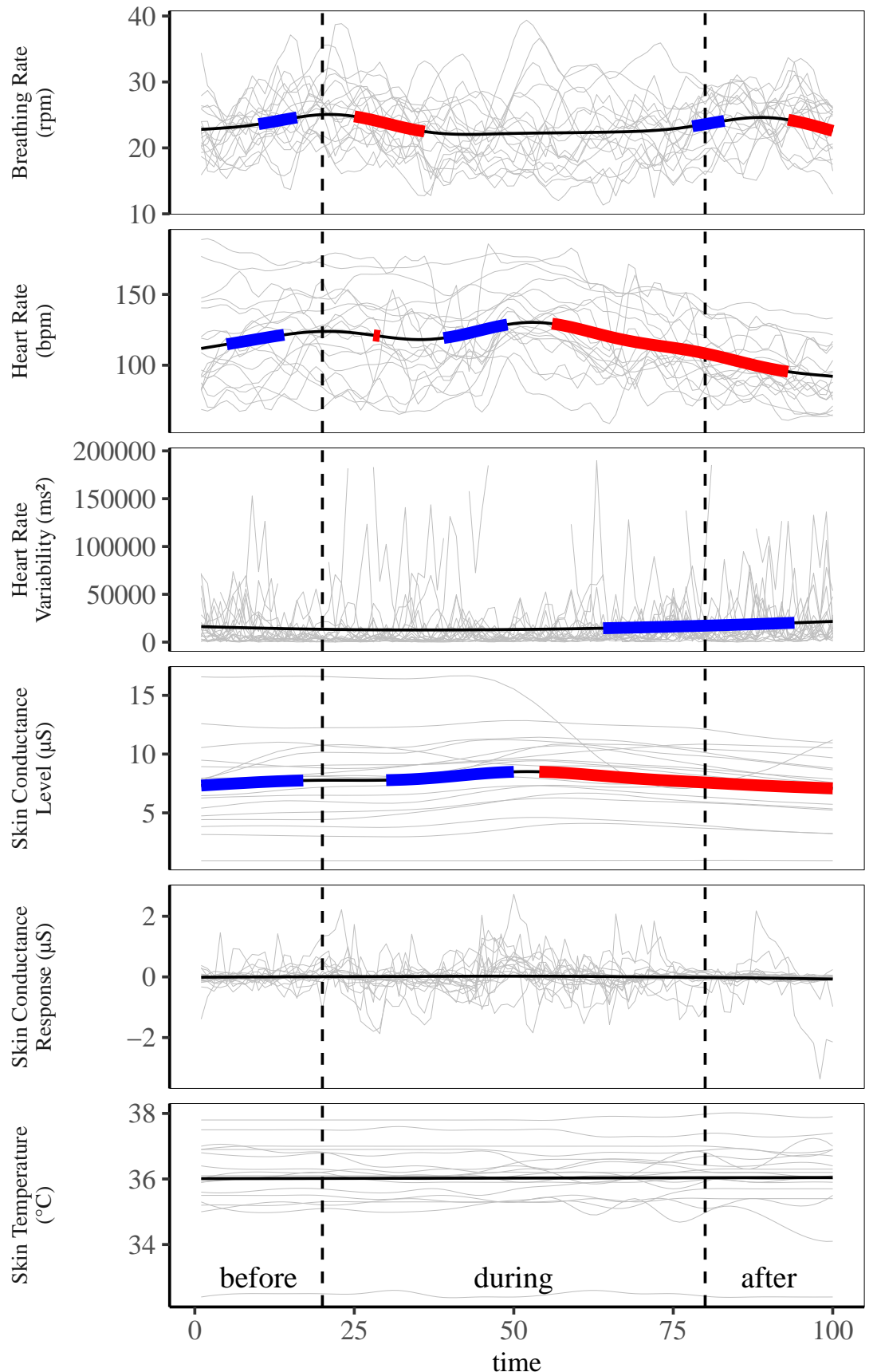

Fig. 4 SiZer analysis of the GAMM predicted values after signal pre-processing treatment and feature extraction. Significant periods are extracted from the first derivatives and reported on the actual GAMM predicted values where red periods indicate a significant decrease and blue periods indicate a significant increase. The period between the dashed vertical lines denotes the zipline activity. Gray time-series represent each participant's individual data. 
Table 2 Comparison of the model fitness with AIC. GAM is the model without random effect or autocorrelation, GAMM no AR1 the model without autocorrelation and GAMM with random effect or autocorrelation.

\begin{tabular}{|c|c|c|c|}
\hline model & GAM & GAMM no AR1 & GAMM full \\
\hline \multicolumn{4}{|l|}{ HR } \\
\hline $\mathrm{df}$ & 9.78 & 5.00 & 6.00 \\
\hline AIC & 16910.35 & 14861.41 & 11186.83 \\
\hline \multicolumn{4}{|l|}{ BR } \\
\hline df & 10.12 & 5.00 & 6.00 \\
\hline AIC & 10583.95 & 9827.13 & 6598.57 \\
\hline \multicolumn{4}{|l|}{ ST } \\
\hline $\mathrm{df}$ & 3.00 & 5.00 & 6.00 \\
\hline AIC & 5574.77 & -1207.23 & -7919.51 \\
\hline \multicolumn{4}{|l|}{ HRV } \\
\hline df & 5.14 & 5.00 & 6.00 \\
\hline $\mathrm{AIC}$ & 42383.69 & 41581.69 & 41308.01 \\
\hline \multicolumn{4}{|l|}{ SCL } \\
\hline df & 5.53 & 5.00 & 6.00 \\
\hline AIC & 9313.66 & 5382.87 & -4761.18 \\
\hline \multicolumn{4}{|l|}{ SCR } \\
\hline $\mathrm{df}$ & 10.66 & 5.00 & 6.00 \\
\hline AIC & 1998.76 & 2039.72 & 1110.50 \\
\hline
\end{tabular}

Table 3 Correspondence of physiological changes with the predicted emotions according to each phase of the zipline activity. The ' + ' sign indicates a significant increase of the physiological measure, the sign '-' a significant decrease and ns. indicates no significant change.

\begin{tabular}{|c|c|c|c|c|c|c|}
\hline \multirow[b]{2}{*}{ Measure } & \multirow{2}{*}{$\begin{array}{l}\text { before } \\
\text { Anxiety }\end{array}$} & \multirow{2}{*}{$\frac{\text { take off }}{\text { Fear }}$} & \multicolumn{2}{|c|}{ during } & \multirow{2}{*}{$\frac{\text { landing }}{\text { Exhilaration }}$} & \multirow{2}{*}{$\begin{array}{c}\text { after } \\
\text { Relief }\end{array}$} \\
\hline & & & Terror & Triumph & & \\
\hline Heart Rate & + & - & + & - & - & - \\
\hline Breathing Rate & + & - & ns. & ns. & + & - \\
\hline Skin Temperature & ns. & ns. & ns. & ns. & ns. & ns. \\
\hline Heart Rate Variability & ns. & ns. & ns. & ns. & + & + \\
\hline Skin Conductance Level & + & ns. & + & - & - & - \\
\hline Skin Conductance Response & ns. & ns. & ns. & ns. & ns. & ns. \\
\hline
\end{tabular}

SCL. HRV did not increased until the participants reach the platform, which can be interpreted as a negative emotional state due to the potential difficulty of reaching the platform. Finally, a significant decrease in HR, BR and SCL was observed by the end of the activity. This increase could be a reflection of participants' relief after finishing the zipline activity. 


\section{Discussion}

During a zipline activity, significant changes in participants' physiological rhythms were observed. Such changes in physiological rhythms can occur before or after an event [61]. An accurate response to an event is facilitated by a physiological pre-activation [62]: increases in heart rate and breathing rate lead to better blood irrigation of the muscles to provide the best behavioral response to the triggering event. Changes in skin temperature and sudation levels are typical side effects of the increase in heart rate and breathing rate. The skin regulates body temperature by increasing or decreasing sudation levels and thereby assist the body's thermoregulation system in order to maintain its homeostasis. In addition, an increase in hand sudation can also improve the individual's grip, which is particularly relevant in this activity. Thus, antecedent physiological changes are triggered not only by the comparison between sensor inputs and behavioral response expectation but also by the uncertainty of the results of the future behavioral response. Subsequent physiological changes happen because of changes in the physiological rhythms after the event. These are the behavioral responses to the event so that the body can adjust to a new accurate behavior depending on the consequences of the previous behavior [63].

Despite improvements in multimodal sensor recording and their decreased size, improvements to the shape and size of associated belts and wristbands can be made, particularly for the purposes of sport monitoring. Indeed, sensors can affect individuals' performance due to their inconvenience (e.g. the sensors can cause discomfort and a heightened awareness that data is being recorded can make the individuals uncomfortable). Furthermore, the EDA sensor on the finger may bother or limit the range of the movement for the user, highlighting the need for less obtrusive sensors [64]. This is particularly the case for sports involving the use of the hands to grip or manipulate the environment as well as for sports involving handlebars, steering wheels or sticks such as driving, cycling or skiing. While the use of EDA sensors in the former is limited, their use in the latter is promising. Therefore, future research should consider changing the sensor placement. For example, the thenar and hypothenar eminence or foot sites could be used instead of the proximal phalanx to measure EDA activity. This may reduce distortion in the data due to the sensors rubbing against the zipline equipment.

While the naturalistic environment is an advantage of the current study, recording physiological measurement of outdoor activities is difficult. The context itself is a challenge due to the vibration which can interfere with the measurements taken. Contrary to lab experiments, field experiments bring a high percentage of artifacts and corrupted data. For example, some incoherent data from the Global Positioning System coordinates, HR, ECG and EDA measures had to be removed in this study. Other technical limitations such as battery life of the sensors and potential network disconnection provide additional problems that need to be solved. The accurate synchronization of data streams is also a challenge. These limitations need to be taken into account 
for the monitoring of athletes in practice contexts and measures can be implemented to reduce the effect of artifacts and corrupted data in the analysis. Simple measures to implement would be to increase the number of participants and to increase the number of repeated measures in the experimental design.

Furthermore, there are some limitations to the experiment design. As participants were not asked to disclose their familiarity with ziplining and other extreme sports, it is possible that some had prior experience of highly sensational activities such as bungee jumping, skydiving or even ziplining. The extent to which experienced participants are emotionally influenced by such activities is likely to be less than novice participants. However, if this is the case, the effect size found in the current paper is likely to be underestimated in comparison with the true effect size. To take this participant effect into account, future investigations could use a repeated measure design to measure the potential decrease within participants' emotional response (e.g. comparing multiple laps on multiple days in motor sports or repeated trail/slopes for downhill biking/skiing/snowboarding). An alternative procedure would be to perform a repeated measurement experiment design by comparing zipline slope angles and lengths in a randomized order to evaluate the intensity of participants' physiological response.

Finally, even if contextual and technical variables are controlled between the participants, inter-individual variables continue to be a potential limitation. For example, although all participants wore the closest fitting belt size, differences in body shape and size still led to minor artifacts in the data streams. Similarly, it is difficult to control for participants' overall health, diet, resistance to cold weather and even their mood on the day, all of which can influence the recording of physiological measurement. Even if the participant experiences warmth or cold during emotional experiences, the external temperature variability for each participant is low. As the duration of the zipline activity was less than 10 minutes, it is likely that the time period was too short for fluctuations in the skin temperature data. Skin conductance response is derived from the electrodermal activity which in turn occur due to an affective response to a specific stimuli. The distribution of the skin conductance data reveal that these responses were limited during experiment. Rather, the electrodermal activity in the current study reflect a general level of stress rather than specific stimuli responses.

By measuring physiological changes during an outdoor activity which involves little to no exertion, this study reveals there is a significant influence of psycho-emotional states on the manifestation of physiological rhythms. While wearable sensors are becoming more common in the evaluation of athletes' performance, the importance of taking psycho-emotional states into account for monitoring athletes is essential when interpreting results from the sensors. Even if it is difficult to separate the physical exertion from the psychoemotional influence, the latter play an important role in athletic performance for many of sports $[65,66]$. 


\section{Conclusion}

Wearable technologies can provide substantial physiological data, allowing individuals to monitor their performance during physical activity. Knowing when heart rate, breathing rate or electrodermal activity changes is essential for the production and reproduction of high-performance activities. It is even more important to understand why these physiological signals change. Among the factors underpinning physiological changes, athletes' emotions have a clear influence on performance even if it is difficult to measure this influence. In this study, ziplining offers a convenient setting to evaluate the variability of physiological rhythms during activities which are otherwise highly similar across several trials. As physiological changes triggered before or after an event are related to the context rather than physical exertion, their variability is a relevant indicator of whether athletes' decision making process is correct. By monitoring physiological changes, it is possible to analyse the optimal patterns and thereby infer individuals' psychological response that occurs during outdoor activities. Taking the influence of athletes' psychological states into account can provide important information for athletes to evaluate their progress, helping them to differentiate between emotion and exertion.

\section{Acknowledgement}

The authors thank the anonymous reviewers for their insightful comments and suggestions. The authors also would like to thank the developers of the following $\mathrm{R}$ packages used to process, analyse, display and report data: $\mathrm{R}$ [67] and the R-packages broom [68], captioner [69], dplyr [70], facetscales [71], forcats [72], ggplot2 [73], ggpubr [74], gridExtra [75], gtools [76], here [77], kableExtra [78], magrittr [79], mgcv [51-53], nlme [80], papaja [81], plyr [70, 82], png [83], purrr [84], readr [85], stringr [86], tibble [87], tidyr [88], and tidyverse [89].

\section{References}

1. Poh M-Z, Loddenkemper T, Swenson NC, Goyal S, Madsen JR, Picard RW (2010) Continuous monitoring of electrodermal activity during epileptic seizures using a wearable sensor. In: International conference of the engineering in medicine and biology society. pp 4415-4418

2. Jain PC (2011) Wireless body area network for medical healthcare. IETE Technical Review 28:362-371. https://doi.org/10.4103/0256-4602.83556

3. Picard RW, Fedor S, Ayzenberg Y (2016) Multiple arousal theory and daily-life electrodermal activity asymmetry. Emotion Review 8:62-75. https : //doi.org/10.1177/1754073914565517

4. Picard RW (2009) Future affective technology for autism and emotion communication. Philos T Roy Soc B 364:3575-3584. https://doi.org/10. 1098/rstb.2009.0143 
5. Etemadi M, Inan OT, Heller JA, Hersek S, Klein L, Roy S (2016) A wearable patch to enable long-term monitoring of environmental, activity and hemodynamics variables. IEEE Transactions on Biomedical Circuits and Systems 10:280-288. https://doi.org/10.1109/tbcas.2015.2405480

6. Szczesna A, Nowak A, Grabiec P, Paszkuta M, Tajstra M, Wojciechowska M (2017) Survey of wearable multi-modal vital parameters measurement systems. In: Gzik M, Tkacz E, Paszenda Z, Pietka E (eds) Innovations in biomedical engineering. Springer, Boston, MA, pp 323-329

7. Aroganam G, Manivannan N, Harrison D (2019) Review on wearable technology sensors used in consumer sport applications. Ah S Sens 19:1983. https://doi.org/10.3390/s19091983

8. Wahl Y, Duking P, Droszez A, Wahl P, Mester J (2017) Criterion-validity of commercially available physical activity tracker to estimate step count, covered distance and energy expenditure during sports conditions. Frontiers in Physiology 8:725. https://doi.org/10.3389/fphys .2017.00725

9. Li RT, Kling SR, Salata MJ, Cupp SA, Sheehan J, Voos JE (2016) Wearable performance devices in sports medicine. Sports Health 8:74-78. https: //doi.org/10.1177/1941738115616917

10. Silva P, Dos Santos E, Grishin M, Rocha JM (2018) Validity of heart rate-based indices to measure training load and intensity in elite football players. The Journal of Strength \& Conditioning Research 32:2340-2347. https: //doi.org/10.1519/jsc.0000000000002057

11. Flatt AA, Howells D (2019) Effects of varying training load on heart rate variability and running performance among an olympic rugby sevens team. J Sci Med Sport 22:222-226. https://doi.org/10.1016/j.jsams.2018. 07.014

12. Barrett S (2017) Monitoring elite soccer players' external loads using real-time data. Int J Sport Physiol 12:1285-1287. https://doi.org/10.1123/ ijspp.2016-0516

13. Foster C, Daniels JT, Yarbrough RA (1977) Physiological and training correlates of marathon running performance. Australian Journal of Sports Medicine 9:58-61.https://doi.org/10.2147/oajsm.s141657

14. Hoffman J (2014) Physiological aspects of sport training and performance. Human Kinetics, Champaign, IL

15. Courneya KS, Carron AV (1992) The home advantage in sport competitions: A literature review. J Sport Exercise Psy 14:13-27. https://doi. org/10.1123/jsep.14.1.13

16. Kreibig SD, Samson AC, Gross JJ (2013) The psychophysiology of mixed emotional states. Psychophysiology 50:799-811. https://doi.org/10. 1111/psyp.12064

17. Cavalade M, Papadopoulou V, Theunissen S, Balestra C (2015) Heart rate variability and critical flicker fusion frequency changes during and after parachute jumping in experienced skydivers. Eur J Appl Physiol 115:15331545. https://doi.org/10.1007/s00421-015-3137-5

18. Bourgois JG, Boone J, Callewaert M, Tipton MJ, Tallir IB (2014) Biomechanical and physiological demands of kitesurfing and epidemiology of 
injury among kitesurfers. Sports Med 44:55-66. https://doi.org/10.1007/ s40279-013-0103-4

19. Dupre D, Bland B, Bolster A, Morrison G, McKeown G (2017) Dynamic model of athletes' emotions based on wearable devices. In: International conference on applied human factors and ergonomics. pp 42-50

20. Ulrich RS, Dimberg U, Driver BL (1990) Psychophysiological indicators of leisure consequences. J Leisure Res 22:154-166. https://doi .org/10. 1080/00222216.1990.11969822

21. Siegel E, Geuss M, Stefanucci J (2008) Studying the relationship between emotion and height perception in naturalistic settings. J Vision 8:757757. https://doi.org/10.1167/8.6.757

22. Hanstock HG, Edwards JP, Roberts R, Walsh NP (2018) High heart rate reactors display greater decreases in tear siga concentration following a novel acute stressor. Biol Psychol 133:85-88. https://doi.org/10.1016/j . biopsycho.2018.02.00

23. Kim J (2019) Effects of immersive technology exposure on stress level changes: Comparative analysis of zipline rides and immersive technology. International Journal of Computer Engineering and Information Technology $11: 229-234$

24. Ellsworth PC, Scherer KR (2003) Appraisal processes in emotion. In: Davidson RJ, Scherer KR, Goldsmith HH (eds) Handbook of affective sciences. Oxford University Press, New York, NY, pp 572-595

25. Panksepp J (2004) Affective neuroscience: The foundations of human and animal emotions. Oxford university press, New York, NY

26. Ekkekakis P, Parfitt G, Petruzzello SJ (2011) The pleasure and displeasure people feel when they exercise at different intensities. Sports Med 41:641-671. https://doi.org/10.2165/11590680-000000000-00000

27. Russell JA (2003) Core affect and the psychological construction of emotion. Psychol Rev 110:145-172. https://doi.org/10.1037/0033-295x. 110.1 .145

28. Samuel O, Walker G, Salmon P, Filtness A, Stevens N, Mulvihill C, Payne S, Stanton N (2019) Riding the emotional roller-coaster: Using the circumplex model of affect to model motorcycle riders' emotional state-changes at intersections. Transportation Research Part F: Traffic Psychology and behaviour 66:139-150. https://doi.org/10.1016/j.trf.2019.08.018

29. Hall EE, Ekkekakis P, Petruzzello SJ (2002) The affective beneficence of vigorous exercise revisited. British journal of health psychology 7:47-66. https://doi.org/10.1348/135910702169358

30. Niedermeier M, Einwanger J, Hartl A, Kopp M (2017) Affective responses in mountain hiking - a randomized crossover trial focusing on differences between indoor and outdoor activity. PLoS One 12: https://doi.org/ 10.1371/journal.pone.0177719

31. Oliveira BR, Slama FA, Deslandes AC, Furtado ES, Santos TM (2013) Continuous and high-intensity interval training: Which promotes higher pleasure? PloS one 8: https://doi.org/10.1371/journal.pone.0079965 
32. Bunting CJ (1995) Physiological measurements of stress during outdoor adventure activities. Journal of Experiential Education 18:5-11. https: //doi.org/10.1177/105382599501800103

33. Liu Y, Zhu SH, Wang GH, Ye F, Li PZ (2013) Validity and reliability of multiparameter physiological measurements recorded by the equivital lifemonitor during activities of various intensities. J Occup Environ Hyg 10:78-85. https://doi.org/10.1080/15459624.2012.747404

34. Akintola AA, Pol V van de, Bimmel D, Maan AC, Heemst D van (2016) Comparative analysis of the equivital eq02 lifemonitor with holter ambulatory ecg device for continuous measurement of ecg, heart rate, and heart rate variability: A validation study for precision and accuracy. Frontiers in Physiology 7:391. https://doi.org/10.3389/fphys.2016.00391

35. Burns A, Greene BR, McGrath MJ, O'Shea TJ, Kuris B, Ayer SM, Stroiescu F, Cionca V (2010) SHIMMER ${ }^{\text {TM }}$-a wireless sensor platform for noninvasive biomedical research. IEEE Sensors Journal 10:1527-1534. https: //doi.org/10.1109/jsen.2010.2045498

36. Ray PP, Dash D, De D (2019) Analysis and monitoring of iot-assisted human physiological galvanic skin responsefactor for smart e-healthcare. Sensor Rev 39:525-541. https://doi.org/10.1108/SR-07-2018-0181

37. Kleckner I, Feldman M, Goodwin MS, Quigley KS (2019) Framework for benchmarking mobile sensors in psychophysiological research. https:// doi.org/10.31234/osf.io/a9ju4

38. Corp AE (2017) Apogee metarecorder. https://apps.apple.com/us/ app/apogee-metarecorder/id965930387. Accessed 1 Jun 2020

39. Ltd S (2017) SYNC. https://play.google.com/store/apps/details? id=co.sensum. careful. Accessed 1 Jun 2020

40. Cacioppo JT, Tassinary LG, Berntson G (2007) Handbook of psychophysiology. Cambridge University Press, New York, NY

41. Barrett KE, Barman SM, Brooks HL, Yuan JX-J (2019) Ganong's review of medical physiology. McGraw-Hill Education, New Delhi, IN

42. Malik M, Bigger JT, Camm AJ, Kleiger RE, Malliani A, Moss AJ, Schwartz PJ (1996) Heart rate variability: Standards of measurement, physiological interpretation, and clinical use. Eur Heart J 17:354-381. https: //doi.org/10.1161/01.cir.93.5.1043

43. Godin C, Prost-Boucle F, Campagne A, Charbonnier S, Bonnet S, Vidal A (2015) Selection of the most relevant physiological features for classifying emotion. In: International conference on physiological computing systems. pp $17-25$

44. Lane RD, McRae K, Reiman EM, Chen K, Ahern GL, Thayer JF (2009) Neural correlates of heart rate variability during emotion. Neuroimage 44:213-222. https://doi.org/10.1016/j .neuroimage.2008.07.056

45. Nakasone A, Prendinger H, Ishizuka M (2005) Emotion recognition from electromyography and skin conductance. In: International workshop on biosignal interpretation. pp 219-222

46. Boucsein W (2012) Electrodermal activity. Springer, Boston, MA 
47. Ohman A, Esteves F, Flykt A, Soares JJF (1993) Gateways to consciousness: Emotion, attention, and electrodermal activity. In: Progress in electrodermal research. Springer, Boston, MA, pp 137-157

48. Wood SN (2017) Generalized additive models: An introduction with r. CRC, Boca Raton, FL

49. Zuur A, Ieno EN, Walker N, Saveliev AA, Smith GM (2009) Mixed effects models and extensions in ecology with r. Springer, Boston, MA

50. Wood SN (2011) Fast stable restricted maximum likelihood and marginal likelihood estimation of semiparametric generalized linear models. Journal of the Royal Statistical Society: Series B 73:3-36. https://doi.org/10.1111/ j.1467-9868.2010.00749.x

51. Wood SN, Pya N, Säfken B (2016) Smoothing parameter and model selection for general smooth models. Journal of the American Statistical Association 111:1548-1575. https://doi.org/10.1080/01621459.2016.1180986

52. Wood SN (2004) Stable and efficient multiple smoothing parameter estimation for generalized additive models. Journal of the American Statistical Association 99:673-686. https://doi.org/10.1198/016214504000000980

53. Wood SN (2003) Thin-plate regression splines. Journal of the Royal Statistical Society Series B 65:95-114. https://doi.org/10.1111/1467-9868. 00374

54. Lin X, Zhang D (1999) Inference in generalized additive mixed modelsby using smoothing splines. Journal of the Royal Statistical Society: Series B 61:381-400. https://doi.org/10.1111/1467-9868.00183

55. Loader C (2006) Local regression and likelihood. Springer, Boston, MA

56. Ventura F, Granadeiro JP, Padget O, Catry P (2020) Gadfly petrels use knowledge of the windscape, not memorized foraging patches, to optimize foraging trips on ocean-wide scales. Proceedings of the Royal Society B 287:20191775. https://doi.org/10.1098/rspb.2019.1775

57. Rondonotti V, Marron JS, Park C, others (2007) SiZer for time series: A new approach to the analysis of trends. Electron J Stat 1:268-289. https: //doi.org/10.1214/07-ejs006

58. Chaudhuri P, Marron JS (1999) SiZer for exploration of structures in curves. Journal of the American Statistical Association 94:807-823. https: //doi.org/10.1080/01621459.1999.10474186

59. Gamiz ML, Martinez-Miranda MD, Raya-Miranda R (2018) Graphical goodness-of-fit test for mortality models. Math Popul Stud 25:123-142. https : //doi.org/10.1080/08898480.2018.1477381

60. Sonderegger DL, Wang H, Clements WH, Noon BR (2009) Using sizer to detect thresholds in ecological data. Frontiers in Ecology and the Environment 7:190-195. https://doi.org/10.1890/070179

61. Lazarus RS, Folkman S (1986) Cognitive theories of stress and the issue of circularity. In: Appley MH, Trumbull R (eds) Dynamics of stress. Springer, Boston, MA, pp 63-80

62. Zilio D (2016) On the autonomy of psychology from neuroscience: A case study of skinner's radical behaviorism and behavior analysis. Rev Gen Psychol 20:155-170. https://doi.org/10.1037/gpr0000067 
63. Fanselow MS (2018) Emotion, motivation and function. Current Opinion in Behavioral Sciences 19:105-109. https ://doi.org/10.1016/j.cobeha. 2017.12 .013

64. Peter C, Ebert E, Beikirch H (2005) A wearable multi-sensor system for mobile acquisition of emotion-related physiological data. In: International conference on affective computing and intelligent interaction. pp 691-698

65. Woodman T, Hardy L (2003) The relative impact of cognitive anxiety and self-confidence upon sport performance: A meta-analysis. J Sport Sci 21:443-457. https://doi.org/10.1080/0264041031000101809

66. Beedie CJ, Terry PC, Lane AM (2000) The profile of mood states and athletic performance: Two meta-analyses. Journal of Applied sport Psychology 12:49-68. https://doi.org/10.1080/10413200008404213

67. R Core Team (2019) R: A language and environment for statistical computing. https://www.R-project.org/

68. Robinson D, Hayes A (2020) Broom: Convert statistical objects into tidy tibbles

69. Alathea L (2015) Captioner: Numbers figures and creates simple captions

70. Wickham H, François R, Henry L, Müller K (2020) Dplyr: A grammar of data manipulation. https://CRAN.R-project.org/package=dplyr

71. Oller Moreno S (2019). http://github.com/zeehio/facetscales

72. Wickham H (2019) Forcats: Tools for working with categorical variables (factors). https : //CRAN.R-project.org/package=forcats

73. Wickham H (2016) Ggplot2: Elegant graphics for data analysis. SpringerVerlag New York

74. Kassambara A (2020) Ggpubr: 'Ggplot2' based publication ready plots

75. Auguie B (2017) GridExtra: Miscellaneous functions for "grid" graphics

76. Warnes GR, Bolker B, Lumley T (2020) Gtools: Various r programming tools

77. Müller K (2017) Here: A simpler way to find your files. https://CRAN . R-project.org/package=here

78. Zhu H (2019) KableExtra: Construct complex table with 'kable' and pipe syntax. https ://CRAN.R-project.org/package=kableExtra

79. Bache SM, Wickham H (2014) Magrittr: A forward-pipe operator for r. https://CRAN.R-project.org/package=magrittr

80. Pinheiro J, Bates D, DebRoy S, Sarkar D, R Core Team (2020) nlme: Linear and nonlinear mixed effects models

81. Aust F, Barth M (2020) papaja: Create APA manuscripts with R Markdown

82. Wickham H (2011) The split-apply-combine strategy for data analysis. J Stat Softw 40:1-29

83. Urbanek S (2013) Png: Read and write png images

84. Henry L, Wickham H (2019) Purrr: Functional programming tools. https://CRAN.R-project . org/package=purrr

85. Wickham H, Hester J, Francois R (2018) Readr: Read rectangular text data. https : //CRAN.R-project .org/package=readr 
86. Wickham H (2019) Stringr: Simple, consistent wrappers for common string operations. https ://CRAN.R-project.org/package=stringr

87. Müller K, Wickham H (2019) Tibble: Simple data frames. https:// CRAN.R-project.org/package=tibble

88. Wickham H, Henry L (2020) Tidyr: Tidy messy data. https://CRAN . R-project.org/package=tidyr

89. Wickham H, Averick M, Bryan J, Chang W, McGowan LD, François R, Grolemund G, Hayes A, Henry L, Hester J, Kuhn M, Pedersen TL, Miller E, Bache SM, Müller K, Ooms J, Robinson D, Seidel DP, Spinu V, Takahashi K, Vaughan D, Wilke C, Woo K, Yutani H (2019) Welcome to the tidyverse. Journal of Open Source Software 4:1686. https://doi.org/10.21105/joss . 01686 